\title{
Maçonaria, religião e culto cívico na atuação de Euclides de Vasconcelos César no Ceará da década de 1920
}

\section{Freemasonry, religion and civic service at Euclides de Vasconcelos César acting in Ceará 1920s}

\author{
Marcos José Diniz Silva \\ Doutor em Sociologia. Professor do Curso de História Universidade Estadual do Ceará-UECE, Brasil \\ Professor do Mestrado Acadêmico em História-MAHIS-UECE. Contato: marcos.diniz@uece.br
}

DOI: http://dx.doi.org/10.15517/rehmlac.v8i1.24280

Fecha de recibido: 18 de enero de 2016 - Fecha de aceptación: 23 de marzo de 2016

\section{Palavras-chaves}

Maçonaria, religião, culto cívico, espiritismo, teosofia, imprensa.

\section{Key words}

Freemasonry, religion, civic cult, spiritism, theosophy, press.

\section{Resumo}

Este artigo trata da atuação do escritor, professor e jornalista Euclides de Vasconcelos César, na cena pública do Ceará dos anos de 1920, pondo em destaque, por um lado, seu papel intelectual através da imprensa, como defensor da liberdade e igualdade religiosas, do Estado laico republicano e, por outro lado, analisando-se sua atuação como agitador cultural através da criação da Academia Polimática, promovendo a instrução pública, o culto cívico e a defesa da fraternidade universal. De pertença maçônica e espirita, e sólida cultura positivista, Euclides César se fará também elemento de promoção de redes de solidariedade intelectual espiritualista de caráter diverso, capazes de fazer frente à acirrada oposição do clero católico local.

\begin{abstract}
This article studies Euclides de Vasconcelos Caesar's performance as a writer, teacher and journalist, on the public stage of Ceará in the 1920s, highlighting, on the one hand, his intellectual role through the press, as a defender of religious freedom and equality, and supporter of a republican and secular state, on the other hand, analyzing his performance as a cultural agitator through the creation of Polimática Academy, promoting public education, civic service and the defense of universal brotherhood. As a Freemason and spiritualist as well as having a solid positivist culture, Euclid Caesar will also promote the networking element of intellectual solidarity among spiritualist of different character, enabling them to cope with the fierce opposition of the local Catholic clergy.
\end{abstract}

\section{Introdução}

A década de 1920, no Brasil, fora marca pelo avanço da modernização capitalista alicerçada hegemonicamente na economia agroexportadora do café, num processo ainda incipiente de industrialização, mas apresentando um crescente índice de diversificação social, 
urbanização e intensificação os debates políticos e intelectuais que colocavam em cheque o modelo político liberal-oligárquico vigente, especialmente com o avanço do movimento operário, da atuação política insurgente de militares de classe média, através do movimento denominado Tenentismo, e da difusão de uma nova mentalidade artística e intelectual através da Semana de Arte Moderna (1922).

Importa ressaltar que esses desenvolvimentos não se deram de modo homogêneo no país, circunscrevendo-se mais intensamente na região Sudeste do Brasil. Na outra porção mais povoada, a região Nordeste, onde se situa o estado do Ceará, o quadro é diverso e periférico ao sistema, predominando uma economia agrária assentada na exportação de açúcar e algodão e na atividade pecuarista, com baixo índice de industrialização e manutenção de padrões mais tradicionais de organização social e de costumes menos afetados pela modernidade. Contudo, nesses estados, como no Ceará, crescia o influxo das ideias e movimentos da modernidade no campo das ideias e anseios modernização econômica e social faziam-se presentes na literatura, na imprensa, nos debates políticos e sociais, além das novas configurações do campo religioso nacional após o advento da República, em 1889.

Nesse contexto difundiam-se ideias e movimentos orientados por valores da modernidade, especialmente o cientificismo positivista, evolucionismo, laicismo, liberalismo; assim como novas ideologias da sociedade industrial, como o socialismo e o anarquismo. Também ganhavam vulto correntes como o materialismo e um espiritualismo moderno num embate vigoroso com o tradicionalismo católico romanizador - vide repercussões do Syllabus e dos "erros modernos" do papa Pio IX - e seu laicato organicamente atuante ${ }^{1}$.

$\mathrm{O}$ que decorre no Brasil, entre os finais do século e princípios do século $\mathrm{XX}$, onde estreitam-se laços de afinidade entre os setores afinados com o pensamento moderno e cientificista, onde dão-se as alianças entre maçons, espíritas, teosofistas, socialistas, libertários nos embates com o catolicismo, como apontado por Marcos Jose Diniz Silva ${ }^{2}$ e Eliane Moura Silva $^{3}$; também Jean Pierre Bastian, citado por Fortunato Mallimaci, o identifica como um traço da América Latina, ao afirmar que:

Esta todavia por estudiarse esta formación de um frente liberal [...] que surgió a través de la creacón de redes associativas incluyendo a las lojas, los círculos espiritistas y las

\footnotetext{
${ }^{1}$ Ver Marcos José Diniz Silva, "Redes intelectuais, tradicionalismo e modernismo: religiosidades alternativas no Ceará dos anos de 1920 e 1930", Embornal 3, no. 5 (janeiro-junho 2012): disponivel em http://www.ce.anpuh.org/images/emb n5/7\%20marcos\%20diniz.pdf

${ }^{2}$ Diniz Silva, "Moderno-espiritualismo e espaço público republicano: maçons, espíritas e teosofistas no Ceará" (Tese de Doutorado em Sociologia, Universidade Federal do Ceará, 2009): disponivel em http://www.dominiopublico.gov.br/pesquisa/PesquisaObraForm.do?select action=\&co autor=91634

${ }^{3}$ Eliane Moura Silva, "Entre religião e política: maçons, espíritas, anarquistas e socialistas no Brasil por meio dos jornais A Lanterna e O livre Pensador (1900-1909)", em Espiritismo \& religiões Afro-brasileiras. História e Ciências Sociais, Artur Cesar Isaia e Ivan aparecido Manoel orgs. (São Paulo: Editora Unesp, 2012).
} 
sociedades protestantes, entre otros. Por lo menos la denucia constante que hizo el clero católico de uma tal inteacción debería tomarse em cuenta ${ }^{4}$.

Fortunato Mallimaci acrescenta a insistência do clero ligado à Roma na denúncia dessas redes associativas como uma "conspiración protestante, liberal, masónica y espiritista". No Brasil, fator agravante dessas contradições, sobretudo entre Maçonaria e Igreja Católica após a chamada Questão Religiosa (1872-1873), consistiu na proibição católica de maçons em seus cultos e organizações leigas, forçando-os às práticas religiosas alternativas, mais ou menos afinadas com a filosofia e a ciência, ajustando-se ao espiritismo e ao esotérico maçônico.

É no bojo dessas redes intelectuais onde indivíduos desenvolvem pertencimentos múltiplos que se tomará, no Ceará das primeiras décadas do século $\mathrm{XX}$, a atuação de Euclides de Vasconcelos César (1887-1973), com intensa participação na Maçonaria e no movimento espírita local, além de sua atuação destacada na imprensa e no cenário literário e intelectual de Fortaleza.

Fortaleza, a capital do estado do Ceará, apresenta-se, na década de 1920, marcada por intensos debates sobre questões de ordem sociopolítica e religiosa, expressas através dos diversos jornais, em círculos literários, organizações operárias e religiosas de diferentes matizes. Despontam, de um lado, as lutas operárias entre elementos de orientação anarquista, socialista e dos Círculos Operários católicos e, do outro, os debates no espaço público sobre modernidade, Estado laico, liberdade e igualdade religiosa, num contexto de "rearmamento institucional" da Igreja católica pós a separação do Estado republicano, desde $1891^{6}$.

\section{Euclides César: fragmentos de uma vida. Ou, história numa sociedade de indivíduos}

Objetiva-se, então, analisar nesse contexto cultural dois aspectos das múltiplas atividades de Euclides César. Primeiro, seu engajamento na defesa da liberdade e igualdade religiosa preceituada na Constituição republicana de 1891, especialmente frente aos ataques do clero católico ao Espiritismo, à Maçonaria e suas tentativas de introdução do ensino religioso na escola pública. No segundo momento, sua atuação no terreno jornalístico e literário voltado ao desenvolvimento dos valores cívicos e morais e ao aperfeiçoamento intelectual da nacionalidade, especialmente através fundação da associação cívico-literária Academia Polimática (1922-1924).

\footnotetext{
${ }^{4}$ Fortunato Mallimaci, "Catolicismo y liberalismo: las etapas del enfrentamiento por la definición de la modernidad religiosa em América Latina", La modernidad religiosa: Europa latina y América Latina em perspectiva comparada, Jean-Pierre Bastian coord. (México: Fondo de Cultura Económica, 2004), 25.

${ }^{5}$ Mallimaci, "Catolicismo y liberalismo", 26.

${ }^{6}$ Sérgio Miceli, A elite eclesiástica brasileira (Rio de Janeiro: Bertrand Brasil, 1988).
} 


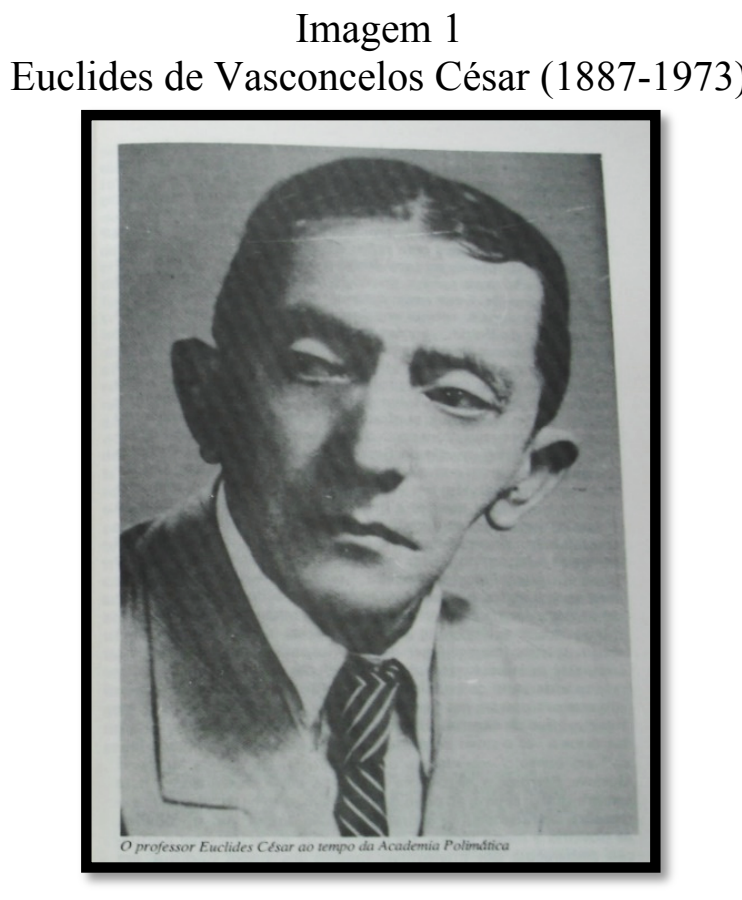

Fonte: Galeno, A praça e o povo, 35.

Para o entendimento da atuação de Euclides César nesses múltiplos setores do campo cultural, privilegia-se sua pertença religiosa e maçônica como elementos delineadores dos valores morais e das condutas cívicas propostas e/ou desenvolvidas em suas atividades, de tal modo que o elemento religioso aparece como realidade histórico-cultural adensada nas demais dimensões da vida e não como fenomenologia essencialista de uma esfera autônoma.

Tomando cautelosa distancia da pretensão biográfica, esse trabalho inspira-se nas reflexões de Norbert Elias sobre a relação individuo/sociedade, quando afirma: "A história é sempre história de uma sociedade, mas, sem a menor dúvida, de uma sociedade de indivíduos" "7. $\mathrm{E}$, mais à frente, questiona os determinismos geradores do que denomina homo clausus:

E embora, ao examinar do alto longos trechos da história, o observador possa notar, primeiramente, como é pequeno o poder individual das pessoas sobre a linha mestra do movimento e da mudança históricos, a pessoa que atua dentro do fluxo talvez tenha uma oportunidade melhor de ver quantas coisas podem depender de pessoas particulares, apesar da fixidez da direção geral ${ }^{8}$.

Contudo, empreender um estudo histórico a partir da atuação de um indivíduo no interior de pequenas ou grandes comunidades, demanda algumas reflexões sobre as condições estruturais

\footnotetext{
${ }^{7}$ Norbert Elias, “A Sociedade dos Indivíduos (1939)”, em A Sociedade dos Indivíduos, Elias ed. (Rio de Janeiro: Jorge Zahar Editor, 1994), 45.

${ }^{8}$ Elias, "A Sociedade dos Indivíduos (1939)", 47.
} 
determinantes nas escolhas individuais, assim como os elementos de autonomia individuais nas suas interações que constituirão as diversas configurações sociais que, mais ou menos intensas e normatizadas, levarão às grandes configurações cristalizadas do mundo social.

Em outros termos, investigar a atuação de grupos $\mathrm{d}(\mathrm{e})$ indivíduos, num determinado contexto sócio-histórico, que guardam similitudes e afinidades eletivas em torno de valores políticos, religiosos e filosóficos, como atores relativamente autônomos no terreno de suas escolhas, plurais em suas disposições e nas teias de suas interdependências; representa um desafio, sobretudo quando se considera que o paradigma dominante nas ciências sociais é o estudo da sociedade.

Norbert Elias ${ }^{9}$, fazendo eco às concepções simmelianas de sociedade, demonstra o insucesso de teóricos como Max Weber e Émile Durkheim, na superação da ideia do homem como Homo clausus, concluindo ter sido Weber influenciado pelo "sentimento de que deve haver algures uma linha de demarcação ou uma divisão entre o que podemos designar como individual e o que pode ser considerado social" ". Daí, tentar distinguir o social e o não-social nas ações dos indivíduos é solucionar o problema pela modelagem do "conceito de indivíduo, parecendo referir-se a uma pessoa aparentemente estática, mais do que a alguém que cresceu, mudou e está ainda a mudar, que está ainda a 'transformar-se""11.

A vertente sociológica durkheimiana ${ }^{12}$ daria realce à distinção singularidade/regularidade à medida que se voltava para os elementos normativos da constituição do social. Das formas mais "inferiores" de sociedade às formas mais complexas, o grau de individualização partiria da total indistinção até aos níveis anômicos de individualismo, provocados pela divisão do trabalho social. Já a abertura de Norbert Elias condiz com a concepção de sociedade como proposta por Georg Simmel: "sociedade de indivíduos", sociedade como interação, sociedade como processo permanentemente alterável pelas interações e interdependências entre os indivíduos, o social como um "todo relacional"13.

Portanto, para além da dicotomia indivíduo/sociedade, Georg Simmel entendia os estudos dos processos de socialização como processos de interação, estudo da sociedade como in status nascens, como movimento incessante. Quisera desvendar esses "modos de interação", elementos

\footnotetext{
${ }^{9}$ Elias, Introdução à Sociologia (Lisboa: Edições 70, 2005).

${ }^{10}$ Leopoldo Waizbort, "Elias e Simmel", em Dossiê Norbert Elias, Leopoldo Waizbort org. (São Paulo: Edusp, 2001), 89-111.

${ }^{11}$ Elias, Introdução à Sociologia. 131.

${ }^{12}$ Émile Durkheim, Da divisão do trabalho social (São Paulo: Martins Fontes, 1995).

${ }^{13}$ Georg Simmel, Estudios sobre las formas de socialización (Madri: Alianza Editorial, [1908]1986). Em Questões fundamentais da sociologia, acrescenta Simmel: "Estaríamos, porém, nos aprisionando ao emprego superficial do termo - certamente útil para a práxis externa - se condicionássemos a denominação de "social" somente às interações duradouras, àquelas que já tenham sido objetivadas em formas que se constituem em unidades perfeitamente caracterizadas como: Estado, família, corporações, igrejas, classes, associações etc. Além destas, porém, há inúmeras formas de relação e modos de interação entre os seres humanos que aparecem em casos isolados de maneira insignificante, mas que, inseridos nas formalizações ditas oficiais e abrangentes, sustentam, mais que tudo, a sociedade tal como a conhecemos". Simmel, Questões fundamentais da sociologia. Indivíduo e sociedade (Rio de Janeiro: Jorge Zahar Editor, [1917] 2006), 16. Grifo do autor.
} 
muitas vezes invisíveis ou "insignificantes" que constituem a sustentação das "interações duradouras" e cristalizadas do social. Enfim, salienta Norbert Elias, "cada pessoa só é capaz de dizer 'eu' se e porque pode, ao mesmo tempo, dizer 'nós, 14 .

É nesse sentido que se pensa as condições sócio-históricas em que os indivíduos interagem desenvolvendo suas trajetórias sociais, com se pretende ver nas interações de que fez parte Euclides César. Pois, levando-se em consideração o papel das instâncias socializadoras básicas, como família, escola, religião, comunidade, notar-se-á que o universo de disposições geradas por essas agências, sobretudo a escolar, fundamental num estudo sobre a dimensão intelectual, não se constituía elemento suficientemente universalizado para definir as bases das disposições intelectuais, profissionais e políticas desses indivíduos.

Constata-se nas últimas décadas do século XIX e primeiros decênios do século XX, as incipientes condições educacionais da população no Ceará, sobretudo no ensino público, como de resto no Brasil, eram compensadas no espaço urbano pela proliferação de iniciativas de educação privada, esforços individuais de autodidatismo exitosos, proliferação de gabinetes de leitura, “escolas populares", associações literárias, científicas, educacionais, beneficentes e filantrópicas; algumas delas instrumentalizando a militância nos movimentos sociais, com forte acento nas intenções modernizantes, reformistas ou revolucionárias.

Poder-se-iam citar diversas dessas entidades, inclusive nas dimensões política e religiosa, que surgiram no Ceará sobretudo nas três últimas décadas do século XIX, impulsionando o desenvolvimento das letras e a formação intelectual e política de pelo menos duas gerações de cearenses, boa parte delas ainda estando em funcionamento até à primeira metade do século XX. Destacam-se: Loja Maçônica Fraternidade Cearense (1859), Seminário Episcopal [da Prainha] (1864), Academia Francesa do Ceará (1872), Escola Popular (1874), Gabinete Cearense de Leitura (1875), Loja Maçônica Igualdade (1882), Escola Normal (1884), Escola Militar do Ceará (1889), Partido Operário (1890), Padaria Espiritual (1892), Academia Cearense [de Letras] (1894), Centro Literário (1894), além de diversos periódicos, alguns claramente ideológicos, como os jornais católicos Tribuna Católica (1867) e o maçônico Fraternidade (1873), que circularam como órgãos exclusivos desses grupos ${ }^{15}$. Registre-se, também, em Fortaleza na virada do século XIX para o XX, certo número de espaços de sociabilidade (letrada) como os cafés (Java, Globo, Riche, Elegante, Comércio, do Pedro Eugênio, etc.), livrarias (Livraria Araújo, Livraria do Oliveira, Livraria Ribeiro, Livraria do Banco do Ceará, Livraria Araripe), praças (do Ferreira, Passeio Público) e repúblicas estudantis ${ }^{16}$.

Muitos indivíduos encontravam nesses espaços de socialização alternativas ou meios de superação das limitações impostas pelo sistema escolar elitista e das carências socioeconômicas das famílias das classes populares. Neles, proporcionavam-se vivências pluralistas de formação

\footnotetext{
${ }^{14}$ Elias, “A Sociedade dos Indivíduos (1939) ", 56-57.

${ }^{15}$ Ver Dolor Barreira, História da literatura cearense (Fortaleza: Edições do Instituto do Ceará, 1986). (Série História do Ceará, Monografia $n^{\circ} 18,1^{\circ}$ Tomo).

${ }^{16}$ Raimundo Girão, Geografia estética de Fortaleza (2 ${ }^{\mathrm{a}}$ Ed. Fortaleza: Banco do Nordeste do Brasil. 1979), 173-205.
} 
de disposições nos agentes sociais, tais como militância no movimento operário, filiação a lojas maçônicas, exercício do jornalismo, participação em clubes literários, frequência a gabinetes de leitura, trabalho em gráficas, tipografias e livrarias, debates e lutas políticas, polêmicas e disputas públicas no campo religioso, enfim, vivências do mundo urbano.

\section{Euclides César: militância socialista, positivista, maçônica e espírita}

Euclides de Vasconcelos César (1887-1973) era natural de Areias, estado da Paraíba. Mudou-se ainda muito jovem para o Ceará, dedicando-se ao magistério particular, como na Escola da Fênix Caixeiral, da associação de trabalhadores homônima, por mais de vinte cinco anos. Em 1917, ingressa como funcionário do Telégrafo Nacional, permanecendo até 1932. O serviço de telégrafo, com seu ar de requinte tecnológico e exigência de razoáveis dotes intelectuais, atraía jovens inteligentes e dinâmicos. Alguns desses telegrafistas se destacariam nas letras, jornalismo e cearense como Demócrito Rocha, Valdemar Falcão, Luiz Memória, Raimundo Alencar Araripe.

Euclides César converte-se ao Espiritismo nesses primeiros anos do século XX, tendo destacada participação nas atividades do Centro Espírita Cearense - fundado em 1910 -, como expositor e coordenador de reuniões evangélico-doutrinárias até à década de 1930. A partir de 1929, torna-se dirigente do Grupo Espírita Auxiliadores dos Pobres, também na capital ${ }^{17}$.

Em 14 de julho de 1919, participara como orador no lançamento do Partido Socialista Cearense, ao lado de outros militantes como Gastão Justa, Joaquim Alves, Eurico Pinto, Raimundo Ramos. Na concentração da Praça Marquês do Herval (atual Praça José de Alencar, no Centro da capital), sob os acordes da banda de música do Batalhão Militar,

Uma multidão imensa se ia formando com grandes levas de companheiros, de todas as classes trabalhadoras, chegadas de todos os pontos da cidade. Minutos após a chegada do diretório fizeram-se ouvir, de uma tribuna improvisada, o companheiro Gastão Justa e o sr. Euclides César, que pronunciaram eloquentes e ardentes improvisos sobre a data de "14 de julho" e sobre a causa do operariado ${ }^{18}$.

Nota-se pela data de lançamento do partido e pelas referencias de Euclides César no discurso, que o "14 de julho" era ainda marcante naquele contexto das lutas sociais e debates intelectuais no Brasil. A "Queda da Bastilha” era uma forte representação veiculada pelos setores

\footnotetext{
${ }^{17}$ Ver Luciano Klein Filho, Memórias do Espiritismo no Ceará (São Paulo: DPL Editora; Fortaleza: Centro de Documentação Espírita do Ceará, 2000).

${ }^{18}$ Ceará Socialista, "O despertar do operariado cearense. Estrondosa manifestação de união. Consolidação do Partido socialista Cearense", 20 de julho de 1919, Apud Adelaide Gonçalves org., Ceará Socialista. Anno 1919. Edição Fac-Similar (Florianópolis: Insular, 2001), 5.
} 
liberais, via maçonaria, em várias instituições operárias de caráter beneficente até pelo menos a década de $1930^{19}$.

Assim, Euclides César estendia sua contribuição intelectual através de conferências nas associações de trabalhadores, como o Sindicato dos Trabalhadores do Porto, Sociedade Deus e Mar, Sociedade Artística Beneficente, defendendo a causa da instrução, da educação moral e cívica, e da liberdade econômica do operariado, além da valorização da mulher. Nesse trabalho, desenvolve parceria com o major Antonio Praxedes Góes, catedrático do Colégio Militar e militante do Positivismo ${ }^{20}$.

Decerto, Euclides César não apenas partilhava a amizade do positivista Major Praxedes, como também era assumido adepto da filosofia comtista. Numa ocasião, em que trata da intolerância religiosa no município de Aracaty $^{21}$, denuncia as perseguições aos maçons locais promovidas por um grupo de religiosas católicos daquela cidade:

A liberdade de consciência é a mais bela das conquistas humanas, proclama o professor Major Praxedes Góes, repetindo os luminosos ensinamentos, contidos na "Política Positiva", do mestre dos mestres - Augusto Comte. Sem ela, a Humanidade não poderia jamais progredir, estaria ainda hoje imersa na antropofagia ${ }^{22}$.

A defesa do livre pensamento foi uma constante, frente à intolerância promovida pelo clero local, de tal modo que, ainda no citado artigo, o autor apela às autoridades públicas:

Seja como for, em nome da Moral e da Razão, e, de acordo com o art. 72 de nossa Constituição, solicitamos para o caso, a esclarecida atenção do Ilustre Presidente do Estado que, estamos certos, não tardará em intervir, como lhe cumpre, em prol da manutenção da ordem material, no sentido de garantir imparcialmente a expansão de quaisquer doutrinas teológicas, metafísicas e científicas ${ }^{23}$.

\footnotetext{
19 "Seguindo a tradição europeia socialista, mas também anarquista, o movimento operário brasileiro se pretendia herdeiro da Revolução Francesa. Essa herança provinha, por um lado, da concepção de que a Revolução fora um primeiro momento em um processo mais amplo que só chegaria a seu término com a vitória do proletariado, o "Quarto Estado"; por outro lado, ela provinha da adesão às ideias da revolução ou àquelas que o movimento operário supunha serem as ideias da Revolução". Cláudio H. de M. Batalha, "Nós, Filhos da Revolução Francesa: a Imagem da Revolução no Movimento Operário Brasileiro no Início do Século XX", Revista Brasileira de História 10, no. 20 (1991): 233-249.

${ }^{20}$ Ver Josênio Parente, Anauê - Os Camisas verdes no poder (Fortaleza: Edições UFC, 1999), 81-87.

${ }^{21}$ Município praiano distante $150 \mathrm{Km}$ da capital Fortaleza, no litoral leste do estado do Ceará. Fora, no século XVIII, um dos primeiros polos econômicos e políticos do Ceará colonial e, mais tarde, seria pioneiro da maçonaria no Ceará, com registros de fundação de loja em 1833, conforme Berenice Abreu, Intrépidos romeiros do progresso. Maçons cearenses no Império (Fortaleza: Museu do Ceará; Secretaria de Cultura do Estado do Ceará, 2009), 58.

${ }^{22}$ Euclides César, "Intolerância religiosa no Aracaty", Gazeta de Notícias, 29 de novembro de 1928.

23 Euclides César, "Intolerância religiosa no Aracaty", Gazeta de Notícias, 29 de novembro de 1928. CONSTITUIÇÃO DA REPÚBLICA DOS ESTADOS UNIDOS DO BRASIL ( DE 24 DE FEVEREIRO DE 1891) "Art.72 - A Constituição assegura a brasileiros e a estrangeiros residentes no país a inviolabilidade dos direitos concernentes a liberdade, a segurança individual e a propriedade, nos termos seguintes: (...) § $3^{\circ}$ Todos os indivíduos
} 
Seus pontos de vista sobre diversos problemas da sociedade brasileira e cearense demonstram coerência com sua cultura positivista e seus pertencimentos maçônico e espiritista em aplicação, seja nas polêmicas combatendo as pretensões da igreja católica de introdução do ensino religioso nas escolas públicas, seja na defesa do lugar prioritário da educação e instrução do operariado em seu projeto de ascensão social, ou na defesa e enaltecimento da mulher como reserva moral da sociedade, dentre outras questões.

A causa da mulher sempre teve lugar em suas lutas e ideais. Na Academia Polimática, como se verá adiante, dedicavam-se conferências e comemorações, inclusive com a participação especial do positivista Major Praxedes. Euclides César combatia os preconceitos à luz da doutrina do "mestre dos mestres". Na polêmica da mulher no mercado de trabalho escrevera:

Há quem seja contrário ao ingresso da mulher nas repartições públicas, principalmente quando por vezes se pretere um pobre pai de família que tem de ceder o lugar a uma senhorita filha de pais opulentos e que por isso mesmo emprega o dinheiro do ordenado na futilidade e no luxo. De um modo geral, porém, vedar o acesso da mulher nas funções públicas, é simples preconceito milenário. A mulher pode ser, não somente a colaboradora eterna do homem na vida planetária como também competir com ele em todos os ramos da atividade intelectual ${ }^{24}$.

Desponta de suas colocações um claro posicionamento frente à "função social" da mulher. Seu lugar deveria ser garantido por sua capacidade produtiva, intelectual e moral; enquanto que se deveria imunizá-la contra o "sectarismo tartufo, explorador das massas". Caberia, pois, defendê-las das "garras aduncas" dos falsos beatos exploradores da ignorância das massas. ${ }^{25}$ Sem dúvida, sua perspectiva religiosa divergia da orientação da igreja católica dirigida à mulher, que circunscrevia sua missão ao lar e à autoridade moral e intelectual do homem; como também legitimando as práticas religiosas populares vistas pelo autor como misticismo. Referia-se, indiretamente, a lideranças como a do Padre Cícero, do Juazeiro do Norte - região sul do estado, o "Cariri cearense" -, e seu séquito de beatas promovendo a difusão de supostos milagres. ${ }^{26}$ Todavia, o autor mostra também, ao referir-se à "vida planetária", uma perspectiva cósmica ao inserir a problemática social da mulher no contexto evolutivo planetário, condizente com a abordagem evolucionista espírita.

À mesma época que adere ao Espiritismo, Euclides César inicia-se na Maçonaria. No final da década de 1920, com a grande cisão no Grande Oriente do Brasil (1928) que resulta na criação das Grandes Lojas estaduais, Euclides César já se encontra como destacado defensor desse movimento. Participa como membro fundador e orador de novas lojas, tais como a "Fortaleza $\mathrm{N}^{\mathrm{o}}$

e confissões religiosas podem exercer pública e livremente o seu culto, associando-se para esse fim e adquirindo bens, observadas as disposições do direito comum."

${ }^{24}$ Euclides César, "A mulher nas repartições", A Razão, 9 de dezembro de 1930.

${ }^{25}$ César, "A mulher nas repartições".

${ }^{26}$ Ver Ralph Della Cava, Milagre em Joaseiro (Rio de Janeiro: Paz e Terra, 1976). 
3" (1928) e "Deus e Fraternidade No 4" (1929), filiadas à Grande Loja Maçônica do Estado do Ceará. Nessa nova potência maçônica, Euclides César ocuparia posteriormente os cargos de "Grande-Orador" (1933-1936), "Grão-Mestre Adjunto" (1935) e “Grande-Orador Adjunto" $(1937-1938)^{27}$.

O acirramento da oposição chegou ao seu limite em 1927, quando o Supremo Conselho desligou-se do G.O.B., levando consigo 108 lojas, configurando, na opinião de Marcelo Linhares "a maior cisão no mundo maçônico brasileiro"28. A partir de então passam a se organizar em cada estado da federação as Grandes Lojas Simbólicas, vinculadas à Confederação da Maçonaria Simbólica, "gozando da mais absoluta soberania, não dependendo de nenhum outro Corpo ou organização maçônica, dentro ou fora do País"29.

$\mathrm{Na}$ imprensa cearense, nos anos de 1927 e 1928, a controvérsia tornou-se frequente, com muitos ataques, apelos e debates em torno de questões maçônicas que não eram do entendimento público. As colunas dos jornais, com posições opostas, nessa polêmica, denunciavam um diálogo maçom-maçom, desde que a população não era esclarecida sobre o fato. De um lado, jornais como $O$ Ceará e $O$ Povo, defendiam o G.O.B. e seu representante máximo, Octavio Kelly, acusando os oposicionistas de aventureiros, maus maçons e desinformados ${ }^{30}$. Do outro lado, os adeptos da reforma, autodenominados progressistas, apoiados pelo jornal Gazeta de Notícias, acusavam o G.O.B. de incompetência administrativa, centralismo, mau uso dos recursos e contribuições, corrupção e conservadorismo.

Como importante liderança da "reforma", Euclides César, sempre opinando nos periódicos locais, num dos vários artigos escritos sobre o tema, conclama os irmãos aos "princípios elevados":

A polêmica entre nós é um gênero perigoso de literatura, porque quase sempre envereda pelo terreno pessoal. Afastam-se as ideias que são substituídas por personalidades. Tal tem sido a tática de maçons que, usando de pseudônimos, investem contra a reforma da Maçonaria inspirada que é, nos mais elevados princípios regeneradores ${ }^{31}$.

\footnotetext{
${ }^{27}$ Luiz de Mello Filho, Maçonaria no Ceará. Lojas e obreiros (Fortaleza: [s.n.], 1973).

${ }^{28}$ Marcelo Linhares, História da Maçonaria (Primitiva, Operativa, Especulativa) (Londrina (PR): Editora Maçônica A Trolha, 1997), 172.

${ }^{29}$ Linhares, História da Maçonaria, 6-8.

${ }^{30}$ O jornal O Ceará, em matéria intitulada "Pela Maçonaria", do dia 11 de fevereiro de 1928, afirmava: "Desaparecer o Grande Oriente do Brasil é desaparecer da pátria o propulsor de sua Independência, da República! Jamais poderá desaparecer! Não é a cizânia e a felonia de alguns maus maçons que isso conseguirá. Não, Ss. Behring \& Cia.! O Grande Oriente do Brasil tem à sua frente a individualidade inconfundível de Octávio Kelly [...]."

${ }^{31}$ César. “A Questão Maçônica”, Gazeta de Notícias. 01 de março de 1928.
} 


\section{Euclides César e a Academia Polimática: culto cívico, vivência literária e agitação cultural}

Euclides César também era muito conhecido como professor de línguas, especialmente de inglês e francês. Entraria para o círculo literário e jornalístico local. Aliás, naquele contexto, essas duas áreas de atuação intelectual se influenciavam mutuamente fazendo que, por um lado, o jornalismo se beneficiasse da cultura e dotes literários de seus praticantes e, por outro, servindo de espaço de trabalho e meio de difusão dos interesses literários desses mesmos jornalistas. Embora se possa afirmar que nem todos os literatos, necessariamente, dependessem do trabalho jornalístico, não se pode negar o volume considerável de escritores, por algum tempo, atuaram na imprensa local; valendo o mesmo para todo o Brasil.

$\mathrm{Na}$ imprensa de Fortaleza, Euclides César foi redator do jornal $O$ Ceará $^{32}$, colunista e colaborador assíduo do A Razão; marcou presença nos jornais $A$ Esquerda ${ }^{33}$, O Povo ${ }^{34}$ e Gazeta de Notícias $^{35}$, dentre outros, com inúmeros artigos sobre temas de interesse nacional, local e quotidiano; assuntos que iam da reforma ortográfica às traquinagens de crianças nas calçadas da cidade.

Euclides César era um agitador cultural com claras intenções cívicas, morais, espiritualistas, nacionalistas, liberais e democráticas. Estivera na dianteira do Grêmio Literário Cearense, entre 1917 e 1919, com Eurico Pinto e Moacir Caminha, e na Academia dos Novos (1920). Contudo, sua atuação mais destacada dar-se-ia quando funda Academia Polimática, que funcionaria até 1924 .

Não tendo sido poeta, nem romancista de renomada, mas cronista que marcou a cultura cearense de seu tempo, Euclides César não está na galeria dos escritores cearenses e, parece que não o interessava o título de literato, pois recusou convite para a Academia Cearense de Letras, em 1930, sendo substituído pelo empresário e líder presbiteriano, Natanael Cortez ${ }^{36}$.

Escrevera uma novela anticlerical intitulada "Nas garras do abutre"; os folhetos "Sara", "O Terror"; diversas crônicas e os "famosos" "Florilégios", perfis biográficos de aproximadamente trezentas personalidades cearenses contemporâneas. Porém, é na citada Academia Polimática, que funcionou em Fortaleza entre 1922 e 1924, que se podem perceber as muitas facetas desse intelectual, a abrangência de suas relações e as bases de seu idealismo, alimentado nas diversas instituições e movimentos a que pertencia.

\footnotetext{
${ }^{32}$ Fundado em 1927 por Júlio de Matos Ibiapina, maçom e professor do Colégio Militar. Considerado o periódico mais anticlerical do jornalismo local.

${ }^{33}$ Fundado em 1928 pelo advogado, escritor e militante comunista Jader de Carvalho.

${ }_{35}^{34}$ Fundado em 1928 por Demócrito Rocha, dentista e escritor. Iniciado na maçonaria nesse mesmo ano.

35 Fundado em 1927 por Antônio Drumond e Teodoro Cabral, ambos maçons e espíritas, proprietário e redator/diretor, redator e cronista respectivamente.

${ }^{36}$ Ver Dolor Barreira, História da literatura cearense (Fortaleza: Edições do Instituto do Ceará, 1986).
} 
Fundada em 12 de novembro de 1922, a Polimática funcionaria até julho de 1924. Tinha sua sede no mesmo prédio onde funcionava a Loja Teosófica Unidade. Congregava sócios das mais variadas atividades, crenças, tendências políticas e filosóficas, a exemplo do maçomteosofista Moraes Correia, o líder católico Andrade Furtado, o positivista Antônio Praxedes Góes, o teosofista César Magalhães, o maçom Demócrito Rocha, o socialista Jader de Carvalho, o pastor presbiteriano Natanael Cortez e o monsenhor Tabosa Braga, dentre muitos outros.

A princípio, essa associação ou movimento, como quiseram alguns seus contemporâneos, pode ser definida como um grêmio cívico-literário. De fato, houvera na programação da Polimática um forte acento literário, porém de sentido amplo à medida que das letras se procurava extrair o espírito, a instrução, a formação. Até o presente momento, aqueles que se referiram à Academia Polimática, excetuando-se Wilson Bóia ${ }^{37}$ - seu mais criterioso estudioso-, limitaram-se a vê-la como mais um movimento literário que agitou efemeramente a capital cearense nos idos de 1920. É o caso do historiador Raimundo Girão, para quem a Polimática consistia em "estranho assanhamento literatureiro, numeroso, palavroso, estrondoso, imaginado por Euclides César" 38 . Contudo, Raimundo Girão concede substancioso parágrafo à descrição daquela inusitada associação:

Ferveu em discursos, moções, protestos, comemoração cívica toda aquela avalancha de "espirituais confrades" e era este o seu tratamento mútuo, convencidos, superconvencidos da pujança de sua assembleia imensa, de mais de dois mil sócios. A Polimática é um fato - gritavam aos quatro ventos. Amemo-nos e eduquemo-nos uns aos outros - eis o lema que os devia conduzir. Além do Espiritualismo [Espiritualíssimo] Confrade ou presidente, que era Euclides César, uma caterva de nomes ilustres: Luís de Moraes Correia, Cursino Belém, Antônio Furtado, Perboyre e Silva, Eduardo Mota, Caio Lemos, Aníbal Mascarenhas, Rodrigues de Andrade, Elias Malmann, César Magalhães, Sobreira Filho, Moésia Rolim, Rubens Falcão, Wallter Pompeu, Eurico Pinto, Henrique Soares, Hélio Caracas, Sidney Neto, Almeida Genú. Nenhum estatuto, nenhuma regra coatora. Qualquer que fosse o tema, seria tema digno de discussão. Não permitidos, entretanto, os apartes. Que se aguardasse o potencial aparteante para falar depois, livre, à sua vez, de interrupções. Original academia essa que, em verdade, como disse Leonardo Mota, assinalou um instante vibrátil na vida fortalezense ${ }^{39}$.

A citação acima, extensa e quase indesculpável, pode se justificar pela necessidade de alguns esclarecimentos. Primeiro, o senão literário do autor para com o caráter "literatureiro, numeroso, palavroso, estrondoso", da Polimática; para, em seguida ressaltar seu teor mobilizatório. No segundo momento, o historiador lista a "caterva de nomes ilustres" que a compunham, desfilando uma fração de nomes. Observe-se que "caterva" pode referir-se a grande

\footnotetext{
${ }^{37}$ Wilson Boia, Associações literárias de Fortaleza (1910-1930) (Fortaleza: Secretaria de Cultura, Turismo e Desporto, 1988).

${ }^{38}$ Girão, Geografia estética de Fortaleza, 193.

${ }^{39}$ Girão, Geografia estética de Fortaleza, 193-195. Grifo do autor.
} 
quantidade de pessoas, animais ou coisas (!), como também agrupamento de pessoas de má índole, mau comportamento, corja, malta...

Essa postura crítica do autor pode ser de fundo meramente literário, suas expressões poderão ser meros recursos estilísticos, como podem, também, denotar discordâncias do autor contemporâneo daquele movimento - com as ideias de muitos de seus destacados membros; haja vista ter sido a Polimática idealizada por um maçom-espírita e frequentada por diversos adeptos da Maçonaria, do Espiritismo e da Teosofia que ocuparam, com grande frequência, o espaço da tribuna para tratar de temáticas direta ou indiretamente ligadas às suas convicções. Ou mesmo para, através da legitimação intelectual auferida por aquela entidade, fortalecer taticamente os laços de afinidade, fortalecendo aquela rede intelectual modernista e espiritualista. Talvez o incômodo barulho dessas heterodoxias é que animassem o referido autor a trata-los com "caterva de nomes ilustres".

Ainda no quadro das considerações sobre a Academia Polimática, no conjunto dos movimentos literários fortalezenses, Edgar Alencar ao rememorar o ano de 1922, acrescenta: "Nesse ano, do Centenário da Independência, se funda a Academia Polimática, associação que teve rápida, mas rumorosa existência. Não era propriamente uma associação, era um movimento. Quase um comício"

Ressaltando o papel fundador de Euclides César, o autor credita a fórmula mais livre e "rumorosa" da Polimática, como alternativa ao formalismo disciplinado e os apertados espaços das meias dúzias de membros dos tradicionais grêmios literários. Assim, contrariamente, a

Polimática arrebatava tudo. Não havia processo seletivo. Suas sessões se realizavam nas manhãs de domingo, sempre movimentadas. [...] A sala se enchia, muita gente, muito discurso. Aliás, a sessão começava na Praça. Euclides César saía acompanhado de grande cortejo. Era ele o presidente e era ele, principalmente, a Polimática ${ }^{41}$.

Nesse ritmo, o autor dedica duas boas páginas a esse "movimento", pois reconhece que "a fórmula de animação das sessões era válida e de certo modo democrática. Ao invés do formalismo regimental das sessões mornas e ordenadas [...]. Literatura para todo mundo. " Não teve um jornal, menos ainda uma revista, não publicou produções, "não possuiu em nenhum momento a consistência intelectual nem a picardia de uma Padaria Espiritual. Mas isto não estaria nos seus propósitos"

Então, é como um "movimento" que se deve perceber a existência da Academia Polimática. De acordo com Wilson Boia, seu mais dedicado estudioso, a Polimática era:

\footnotetext{
${ }^{40}$ Edgar Alencar, Fortaleza de ontem e anteontem (Fortaleza: Edições UFC; Prefeitura Municipal de Fortaleza, 1980), 148. Grifo nosso.

${ }^{41}$ Alencar, Fortaleza de ontem e anteontem, 148.

${ }^{42}$ Alencar, Fortaleza de ontem e anteontem, 149.
} 
Uma sociedade, ou melhor, uma universidade popular, democrática, voltada para o aperfeiçoamento da natureza humana através do culto da Família, da Pátria, da Mulher, da Humanidade, do Trabalho. Democrática, porque agasalhava em seu seio, numa promiscuidade consoladora e sadia, a mocidade estudiosa, os renomados intelectuais e os humildes filhos do povo. De caráter educativo, batia-se pela regeneração social e pela fraternidade universal ${ }^{43}$.

Portanto, mais que um grêmio fechado para o cultivo elitista das letras, a Academia Polimática se fizera um clube de livre-pensamento, de semeadura dos valores cívicos, morais, de aperfeiçoamento intelectual, de democratização do saber, de mobilização e de fraternidade. Seus comentadores, contemporâneos e participantes, a classificaram como "academia popular de educação", "sociedade cultural", "universidade popular". Se bem observada, sua programação e seus mais atuantes membros, nos seus quase dois anos de existência, revelam a predominância de uma perspectiva de pensamento que, muito frequentemente denominavam de "a ideia nova".

As duas colunas mestras da Polimática consistiam no projeto de "regeneração social" e de "Fraternidade Universal". A ideia de regeneração, de aperfeiçoamento da natureza humana, o investimento no aprimoramento do caráter - polimento da "pedra bruta" maçônica -, como o trabalho de enquadramento evolucionista a ser perseguido na perspectiva espiritista e mesmo teosófica, distanciavam os polimáticos, ou "espirituais confrades" - como se cumprimentavam -, da tradição teológica ocidental judaico-cristã.

Em seu amplo quadro de sócios, entre efetivos, honorários e correspondentes, despontaram nomes das mais variadas tradições de pensamento e crenças religiosas como já observado. Embora contando com membros ligados ao catolicismo, é marcante a ausência desses intelectuais católicos e de suas preocupações nas programações e nos debates e conferências pronunciadas na Polimática ${ }^{44}$.

Acrescente-se, a propósito, que a Polimática aprovou a indicação do nome do arcebispo dom Manuel da Silva Gomes para sócio honorário. Todavia, em ofício do "Palácio Arquiepiscopal de Fortaleza", de 13 de agosto de 1923, dirigido ao $1^{\circ}$ secretário da Academia Polimática, César Magalhães, dom Manuel agradece a deferência e, justificando a impossibilidade de participar da entidade em virtude dos "múltiplos e absorventes deveres de meu ministério pastoral", aceita o convite com a condição de "aplaudir de longe, como mero expectador, a seus triunfos literários". ${ }^{45}$ Mas, não se pode olvidar que, naquele cenário, maçons, espíritas e teosofistas eram quase diariamente atacados pelo jornal $O$ Nordeste, órgão da

\footnotetext{
${ }^{43}$ Boia, Associações literárias de Fortaleza (1910-1930), 153. Grifo nosso.

${ }^{44}$ Esse fato pode ser denotativo das contradições internas à entidade, ou sua real finalidade, pois naquele contexto histórico estava a igreja católica no Brasil, em intensa atividade social e política, com seu laicato orgânico, aproximando-se das elites oligárquicas da República, mobilizando o operariado, as classes profissionais, a juventude, as mulheres.

${ }^{45}$ Boia, Associações literárias de Fortaleza (1910-1930), 186.
} 
arquidiocese de Fortaleza, fundado em junho de 1922, muito embora o periódico utilizasse exemplos de outros estados da federação ou de outros países para suas condenações ${ }^{46}$.

A Polimática realizava comemorações das grandes datas históricas e cívicas, como a Independência do Brasil (1822), a proclamação da República (1889), abolição da escravidão (1888), algumas em sessões na Praça do Ferreira; promovia homenagens póstumas a grandes vultos das artes e letras nacionais e estrangeiras, a exemplo de Rui Barbosa e Guerra Junqueiro; promovia moções de protesto contra as guerras e o militarismo, contra a carestia; encetava campanhas de solidariedade; realizava sessões especiais, como a que se destinava à "exaltação da Mulher", ou em cidades próximas a Fortaleza, como Maranguape e Pacatuba; criou uma Liga do Voto Secreto; promovia todo $1^{\circ}$ dia do ano a festa da Fraternidade Universal. Em tudo havia um acento moral, espiritualista, cívico, literário e científico de caráter laico.

Desenvolviam-se no Ceará, como de resto no Brasil daquele contexto republicano, entre amplos setores da intelectualidade, uma intensa campanha de caráter laico, de sacralização cívica do tempo e do espaço da cultura-pátria, forjava-se a construção do panteão cívico, tal qual demonstrara José Murilo de Carvalho ${ }^{47}$ e, para o caso português, Fernando Catroga ${ }^{48}$.

\footnotetext{
${ }^{46}$ Mais detalhes sobre as investidas da imprensa católica contra a maçonaria nos regimes republicanos, ver Marcos José Diniz Silva, "Maçonaria e laicismo republicano na imprensa católica cearense entre os anos de 1910 e 1920 ", Ciência \& Maçonaria I, no. 1 (2013). Para os ataques do clero ao Espiritismo, ver Diniz Silva, "Do espiritococus à fábrica de loucos: o espiritismo sob a retórica da aniquilação na imprensa católica cearense", Revista Brasileira de História \& Ciências Sociais - RBHCS 7, no. 13 (2015).

${ }^{47}$ Ver Jose Murilo de Carvalho, A Formação das Almas. O imaginário da República no Brasil (São Paulo: Companhia das Letras, 1998).

${ }^{48}$ Ver Fernando Catroga, Nação, mito e rito. Religião Civil e comemoracionismo (Fortaleza: Edições NUDOC-UFC / Museu do Ceará, 2005).
} 


\section{Imagem 2}

Procissão cívica da Polimática pelas ruas de Fortaleza-Ce, em 1923.

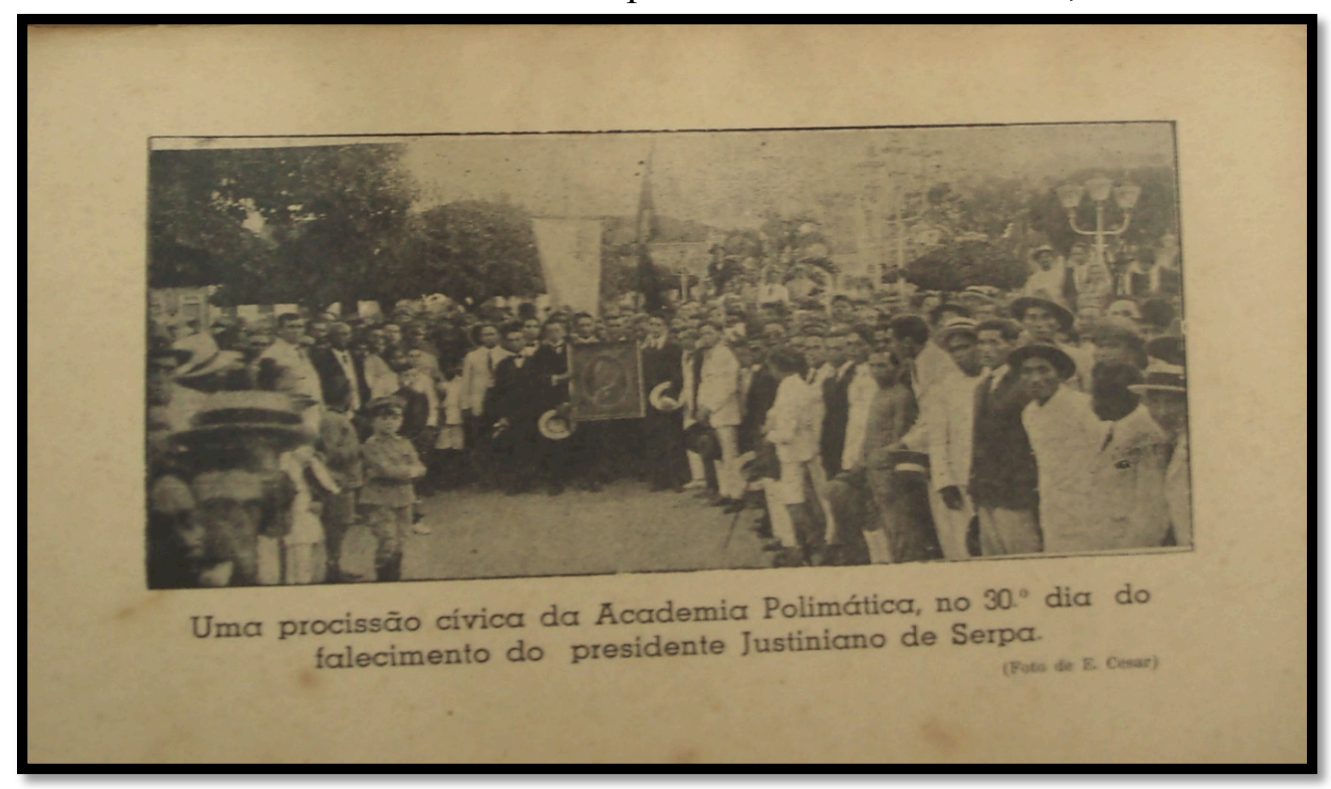

Fonte: Menezes, Coisas que o tempo levou, 105.

Como consta acima, na Imagem 2, representativa dessas atividades, a fotografia da "procissão cívica" foi feita pelo próprio Euclides César, conforme Raimundo de Menezes, homenageava o cearense e ex-governador do estado (chamava-se presidente) Justiniano José de Serpa $^{49}$. A sacralização das festas cívicas prescindia dos recursos de materialização e eternização para o culto posterior e rememoração da sociedade que a tecnologia fotográfica da época permitia.

Atuando como fundador e presidente, "o maior agitador de ideias de minha geração na Praça do Ferreira", no dizer de Djacir Menezes (1907-1996) ${ }^{50}$, secundado por um grupo idealista e militante, alguns bem jovens, Euclides César, transformara a Academia Polimática, também, em espaço para a difusão dos princípios doutrinários das correntes do moderno- espiritualismo ${ }^{51} \mathrm{a}$ que pertenciam, ou simpatizavam, boa parte de seus mais dedicados membros.

Estiveram na linha de frente dos trabalhos, dentre outros, nomes como César Magalhães, Eduardo Mota, Walter Pompeu, Moésia Rolim, Antônio Praxedes Góes, Elias Malmann, Eurico Pinto, Juarez Castelo Branco, Moraes Correia, Caio Lemos ${ }^{52}$. Desse modo, observa-se, dentre os

\footnotetext{
49 Justiniano José de Serpa (1852-1923). Bacharel em Direito advogado, escritor, poeta, várias vezes deputado durante o Império e governador do Ceará republicano, entre 1920 e 1923 . Pertenceu a sociedades literárias e foi fundador da Academia Cearense de Letras.

${ }^{50}$ Citado em Wilson Boia, Associações literárias de Fortaleza (1910-1930), 159.

${ }^{51}$ Diniz Silva, "Moderno-espiritualismo e espaço público republicano".

${ }^{52}$ Observando cuidadosamente o "Relatório das atividades da Academia Polímática", organizado pelo citado Wilson Bóia, e acrescentado de notas sobre a entidade publicadas no jornal A Tribuna, totalizando 102 datas de sessões e
} 
citados acima, certa proeminência de ação de indivíduos ligados à Maçonaria e à Teosofia, especialmente através de Moraes Correia, Caio Lemos e César Magalhães; embora não seja de modo algum descartável o trabalho doutrinário do positivista Major Praxedes Góes.

A proximidade espacial da sede da Academia Polimática com a sede da Loja Teosófica Unidade, pelo fato de estarem do mesmo prédio, fato que não parece não ter sido mera coincidência, mostra ter gerado importantes dividendos para ambos os lados.

Um indicativo dessa íntima relação, pode ser visto nas diversas conferências pronunciadas por teosofistas, com títulos que tratam direta ou indiretamente de temática espiritual; conquanto houvesse, segundo se afirmava, ampla liberdade de opinião para os participantes. Mas, o é certo que, na programação da Academia Polimática, não se registraram conferências ou outras atividades que tivessem em seus títulos referências ao catolicismo ou ao protestantismo, ressalvando-se a possibilidade de terem sido omitidos pelos jornalistas, pelos memorialistas, ou mesmo de terem sido tratados em debates orais sem nenhum registro.

Assim, concretamente, ficaram registradas as conferências teosóficas: "A Estrela do Oriente",53, "A civilização Egípcia", esta apresentada como um "tema científico"; "A verdadeira Fraternidade" e "O Sermão da Montanha", de César Magalhães; "A consoladora certeza da imortalidade", "A clarividência e os segredos da Natureza", "A Religião da Fraternidade", de Caio Lemos; "A limitada harmonia da Natureza", de Moraes Correia.

A conferência "A Estrela do Oriente", desenvolvida em dezembro de 1922, referia-se à Ordem Estrela do Oriente, sobre a qual o autor voltaria a falar na solenidade da Fraternidade Universal, de $1^{\circ}$ de janeiro de 1924. Segundo o jornal $A$ Unidade (Fortaleza-Ce, $1^{\circ}$ de janeiro de 1924), órgão da Loja Teosófica Unidade, a Ordem Estrela do Oriente, "é uma organização internacional, derivada da expectativa rapidamente crescente, visível em muitas partes do mundo, acerca da próxima vinda de um grande Instrutor espiritual [...]".

Tratava-se de um movimento "messiânico", paralelo à Sociedade Teosófica Mundial, com grande adesão dos teosofistas, tendo como chefe mundial J. Krishnamurti, secundado por Annie Besant, sucessora de Helena Blavatsky. A Ordem foi fundada em Benares, Índia, em 1911, depois sediada em Londres. Seu representante geral no Brasil era o general Raimundo Pinto Seidl, também presidente da Sociedade Teosófica no Brasil. A chefia para os estados do Ceará,

outros eventos, pude tabular a frequência de aparecimento dos nomes de seus membros, de tal modo que os dez citados correspondem aos de maior destaque e visibilidade.

${ }^{53}$ A citada conferência, desenvolvida em dezembro de 1922, referia-se à Ordem Estrela do Oriente, sobre a qual o autor voltaria a falar na solenidade da Fraternidade Universal, de $1^{\circ}$ de janeiro de 1924 . Segundo o jornal $A$ Unidade (Fortaleza-Ce, $1^{\circ}$ de janeiro de 1924), órgão da Loja Teosófica Unidade, a Ordem Estrela do Oriente, “é uma organização internacional, derivada da expectativa rapidamente crescente, visível em muitas partes do mundo, acerca da próxima vinda de um grande Instrutor espiritual [...]". Tratava-se de um movimento "messiânico", paralelo à Sociedade Teosófica Mundial, com grande adesão dos teosofistas, tendo como chefe mundial J. Krishnamurti, secundado por Annie Besant, sucessora de Helena Blavatsky. A Ordem foi fundada em Benares, Índia, em 1911, depois sediada em Londres. Seu representante geral no Brasil era o general Raimundo Pinto Seidl, também presidente da Sociedade Teosófica no Brasil. A chefia para os estados do Ceará, Rio Grande do Norte e Paraíba cabia ao maçom Tenente Caio Lustosa de Lemos, conforme o citado jornal. 
Rio Grande do Norte e Paraíba cabia ao maçom, Tenente, professor do Colegio Miliar de Fortaleza, Caio Lustosa de Lemos.

Outro momento de fraternização e difusão dos ideários espiritualistas, no contexto das atividades da Academia Polimática, não apenas para a difusão de seus ensinamentos e propostas de reforma do homem e da sociedade, mas também de afirmação da igualdade e liberdade religiosas, verifica-se na promoção da festa da Fraternidade Universal, em seus dois anos de existência. Na primeira delas, segundo informa Raimundo de Menezes:

Constituiu fato notável a sessão comemorativa da fraternidade universal, levada a efeito em $1^{\circ}$ de janeiro de 1923, no 'Clube dos Diários', presidida por Justiniano de Serpa, então presidente do Estado. Houve cinco oradores. Um falou sobre a data em face do catolicismo. Outro, diante do espiritismo. O terceiro, à luz do protestantismo. O quarto, da teosofia e o último, da teoria do positivismo [...]. O então deputado Raimundo Arrais cogitou redigir um projeto de lei considerando a Polimática de utilidade pública. Mas tal ideia morreu no tinteiro $[\ldots]^{54}$.

A simbiose entre as atividades cívico-culturais da Polimática e o movimento teosófico era tal que, no ano seguinte, era a Loja Teosófica Unidade que aparecia como organizadora da dita solenidade, com muita divulgação nas sessões da Polimática, e chamadas no jornal A Tribuna, como relata Wilson Bóia:

Muito comentada a sessão realizada às catorze horas, no salão nobre do Clube Iracema, promovida pela Loja Teosófica Universal [Unidade], na terça-feira de 1 de janeiro de 1924, presidida por Cruz Filho e dedicada ao Culto da Humanidade ou da Fraternidade Universal. Ocuparam a tribuna diversos representantes das mais variadas tendências religiosas: Natanael Cortez, pelo Cristianismo; Francisco Falcão, pela Sociedade Esperanto; Maria José de Castro, pela Academia Polimática; Ten. cel. Heitor G. de Araújo, pelo Instituto Neo Pitagórico, de Curitiba; César Magalhães, pela Ordem Estrela do Oriente; Giovanni Levi, pela Igreja Católica Liberal; Caio Lemos, pela Sociedade Teosófica [Unidade]. ${ }^{55}$

Vê-se, portanto, a presença de movimentos esotéricos substancialmente representados, como a escola ocultista Instituto Neo Pitagórico, do estado do Pananá; a Ordem Estrela do Oriente; além da loja teosófica local. A representação da Igreja Católica Liberal só reforça o caráter heterodoxo dos eventos da Polimática. Tal proeminência dos teosofistas nas atividades da Polimática devia-se, em parte à considerável presença destes entre os maçons, favorecida pelas articulações de Euclides César e, por outra parte, por ser uma das características doutrinárias do movimento teosófico a promoção da fraternidade entre todas as religiões e correntes filosóficas.

\footnotetext{
${ }^{54}$ Raimundo de Menezes, Coisas que o tempo levou... (Crônicas históricas da Fortaleza antiga) (Fortaleza: Edésio Editor, 1938), 105.

${ }^{55}$ Boia, Associações literárias de Fortaleza (1910-1930), 185. Grifo nosso.
} 
Contudo, essas explicações não permitem excluir a possibilidade de que esse movimento de fraternidade espiritualista também representasse uma rede de promoção e autoproteção desses movimentos, eletivamente afinados, ante os ataques virulentos do clericalismo católico; haja vista não ter florescido no estado do Ceará o anticlericalismo como alternativa de luta ou autodefesa desses grupos minoritários, como também é uma característica brasileira.

\section{Considerações finais}

Enfim, depreende-se da breve análise da atuação de Euclides César, no cenário intelectual dos anos 1920, um papel de destaque enquanto mobilizador de pessoas e ideias, divulgador de valores cívicos e morais, assim como defensor enérgico do estatuto laico da República brasileira, acirradamente combatido pelas hostes clericais.

Suas articulações com diferentes instituições, setores intelectuais e correntes de pensamento envolvendo maçonaria, espiritismo, teosofia, protestantismo, dissidências católicas, positivismo e socialismo, assim como sua marca espiritualista e cientificista, vêm revelar, por um lado, as múltiplas possibilidades de ação e interdependência dos indivíduos como portadores/construtores incessantes do social; por outro lado, Euclides César é a encarnação típica do cidadão republicano engajado na promoção de uma cultura cívica e laica, com forte acento positivista num país, como o Brasil, que viu muito cedo o desvanecimento do potencial positivista da República no engendramento de uma nova ordem social.

Assim, a criação da Academia Polimática possibilitou a Euclides César fazer germinar seus projetos de uma república laica e progressista, assentada no culto cívico e na democratização e popularização do acesso à instrução - o acesso à luz -, nos quadros da tradição iluminista maçônica e do evolucionismo espírita que lhe eram tão caros.

\section{Fontes}

Gazeta de Notícias

A Razão

A Unidade

A Tribuna

O Ceará

O Nordeste

\section{Bibliografia}

Abreu, Berenice. Intrépidos romeiros do progresso. Maçons cearenses no Império. Fortaleza: Museu do Ceará; Secretaria de Cultura do Estado do Ceará, 2009. 
Alencar, Edgar. Fortaleza de ontem e anteontem. Fortaleza: Edições UFC/Prefeitura Municipal de Fortaleza, 1980.

Barreira, Dolor. História da literatura cearense. Fortaleza: Edições do Instituto do Ceará, 1986. Série História do Ceará, Monografia n ${ }^{\circ} 18,1^{\circ}$ Tomo.

Batalha, Cláudio H. de M. "Nós, Filhos da Revolução Francesa: a Imagem da Revolução no Movimento Operário Brasileiro no Início do Século XX”. Revista Brasileira de História 10, no. 20 (1991): 233-249.

Bóia, Wilson. Associações literárias de Fortaleza (1910-1930). Fortaleza: Secretaria de Cultura, Turismo e Desporto, 1988.

Carvalho, Jose Murilo de. A Formação das Almas. O imaginário da República no Brasil. $5^{\text {a }}$ reipress., São Paulo: Companhia das Letras, 1998.

Catroga, Fernando. Nação, mito e rito. Religião Civil e comemoracionismo. Fortaleza: Edições NUDOC-UFC/Museu do Ceará, 2005.

Della Cava, Ralph. Milagre em Joaseiro. Rio de Janeiro: Paz e Terra, 1976.

Durkheim, Émile. Da divisão do trabalho social. São Paulo: Martins Fontes, 1995.

Elias, Norbert. "A Sociedade dos Indivíduos (1939)". Em A Sociedade dos Indivíduos. Norbert Elias ed. Rio de Janeiro: Jorge Zahar Editor, 1994.

Elias, Norbert. Introdução à Sociologia. Lisboa: Edições 70, 2005.

Galeno, Alberto S. A praça e o povo (hHomens e acontecimentos que fizeram história na Praça do Ferreira). Fortaleza: Stylus comunicações, 1991.

Girão, Raimundo. Geografia estética de Fortaleza. $2^{\text {a }}$ Ed. Fortaleza: Banco do Nordeste do Brasil (BNB). 1979.

Gonçalves, Adelaide (Org.) Ceará Socialista. Anno 1919. Edição Fac-Similar. Florianópolis: Insular, 2001.

Klein Filho, Luciano. Memórias do Espiritismo no Ceará. São Paulo: DPL Editora; Fortaleza: Centro de Documentação Espírita do Ceará, 2000.

Mallimaci, Fortunato. "Catolicismo y liberalismo: las etapas del enfrentamiento por la definicón de la modernidad religiosa em América Latina”. En La modernidad religiosa: Europa latina y América Latina em perspectiva comparada. Editado por Jean-Pierre Bastian. México: Fondo de Cultura Económica, 2004.

Mello Filho, Luiz de. Maçonaria no Ceará. Lojas e obreiros. Fortaleza: [s.n.], 1973.

Menezes, Raimundo de. Coisas que o tempo levou... (Crônicas históricas da Fortaleza antiga). Fortaleza: Edésio Editor, 1938.

Miceli, Sérgio. A elite eclesiástica brasileira. Rio de Janeiro: Bertrand Brasil, 1988.

Parente, Josênio. Anauê - Os Camisas verdes no poder. Fortaleza: Edições UFC, 1999.

Silva, Eliane Moura. "Entre religião e política: maçons, espíritas, anarquistas e socialistas no Brasil por meio dos jornais A Lanterna e O livre Pensador (1900-1909)". Em Espiritismo \& religiões Afro-brasileiras. História e Ciências Sociais. Artur Cesar Isaia e Ivan aparecido Manoel orgs. São Paulo: Editora Unesp, 2012. 
Silva, Marcos José Diniz. "Moderno-espiritualismo e espaço público republicano: maçons, espíritas e teosofistas no Ceará”. Tese de Doutorado em Sociologia, Universidade Federal do Ceará, 2009. Disponivel em http://www.dominiopublico.gov.br/pesquisa/PesquisaObraForm.do?select_action=\&co_a utor $=91634$

Silva, Marcos José Diniz. "Redes intelectuais, tradicionalismo e modernismo: religiosidades alternativas no Ceará dos anos de 1920 e 1930". Embornal 3, no. 5 (janeiro-junho 2012). Disponivel em http://www.ce.anpuh.org/images/emb_n5/7\%20marcos\%20diniz.pdf

Silva, Marcos José Diniz. "Maçonaria e laicismo republicano na imprensa católica cearense entre os anos de 1910 e 1920”. Ciência \& Maçonaria I, no. 1 (2013). Disponivel em http://www.cienciaemaconaria.com.br/index.php/cem/article/view/4/1

Silva, Marcos José Diniz. "Do espiritococus à fábrica de loucos: o espiritismo sob a retórica da aniquilação na imprensa católica cearense”. Revista Brasileira de História \& Ciências Sociais - RBHCS 7, no. $13 \quad$ (2015). Disponivel em http://www.rbhcs.com/rbhcs/article/view/130/pdf

Simmel, Georg. Estudios sobre las formas de socialización. Madrid: Alianza Editorial, [1908] 1986.

Simmel, Georg. Questões fundamentais da sociologia. Individuo e sociedade. Rio de Janeiro: Jorge Zahar Editor, [1917] 2006.

Waizbort, Leopoldo. “Elias e Simmel”. Em Dossiê Norbert Elias. Leopoldo Waizbort org. São Paulo: Edusp, 2001.

Weber, Max. Economia e Sociedade. Brasília (DF): Editora UnB, 1994. 